\title{
Real-time test-bed system development using power hardware-in-the-loop (PHIL) simulation technique for reliability test of DC nano grid
}

\author{
Kyung-Wook Heo ${ }^{1} \cdot$ Hyun-Jun Choi ${ }^{1} \cdot$ Jee-Hoon Jung ${ }^{1}$ (I)
}

Received: 19 February 2020 / Revised: 5 March 2020 / Accepted: 6 March 2020

(c) The Korean Institute of Power Electronics 2020

\begin{abstract}
Since various power sources such as renewable energy and energy storage systems (ESSs) are connected to the DC grid, the reliability of the grid system is significant. However, the configuration of an actual DC grids for testing the reliability of the grid system is inconvenient, expensive and dangerous. In this paper, a test-bed system made up of a $20-\mathrm{kW}$ DC nano grid and a control algorithm considering an external grid based on power hardware-in-the-loop (PHIL) simulation are proposed to demonstrate the reliability of the DC grid. Using the PHIL simulation technique, target grids can be safely implemented with laboratory-level instruments and simulated by real-time simulators, which emulates grid operations that are similar to the actual grid. In addition, using the proposed control algorithm, the operations of grid-connected converters are demonstrated according to the grid-connected or islanding modes. Finally, the reliability of the simulated DC nano grid and the effectiveness of the grid-connected converter are verified using the PHIL simulation system with 3-kW prototype converters.
\end{abstract}

Keywords Power hardware-in-the-loop (PHIL) simulation · DC nano grid · DC bus signaling (DBS) - Grid power failure · $\mathrm{DC} / \mathrm{DC}$ converter $\cdot \mathrm{AC} / \mathrm{DC}$ converter

\section{Introduction}

As sustainable energy becomes increasingly important due to environmental issues, DC nano grids, like the one shown in Fig. 1, have attracted a great deal of attention [1-3]. In general, the total load of a DC nano grid is less than $20-\mathrm{kW}$, which consists of distributed power, renewable energy sources and energy storage systems (ESS) [4]. Due to the intermittent generation of renewable energy sources, ESSs are required to provide stable power to the grid [5-8]. In addition, it is common to connect an external grid in order to maintain reliability in the event of a grid power failure [9-12].

The operations of a DC nano grid can be divided into a grid-connected mode and an islanding mode [13]. In the grid-connected mode, the main grid supplies electric power to the load, while in the islanding mode, the DC nano grid

Jee-Hoon Jung

jhjung@unist.ac.kr

1 School of Electrical Engineering, Ulsan National Institute of Science and Technology, Ulsan, Republic of Korea operates independently by using an ESS or external grid power. For the reliability of the DC nano grid, smooth mode transition to the islanding mode is essential during grid accidents such as natural disasters or sudden load increments [14]. Therefore, seamless mode transitions between the gridconnected mode and the islanding mode, i.e., an appropriate control algorithm, should be prepared.

To apply a seamless control algorithm in practice, it should be verified by experiments. However, it is difficult to build experimental test-beds. In addition, it takes a great deal of time and money to verify the reliability of the actual power grid. In the past, grid interactions have been analyzed by computer simulations, field experiments and stand-alone hardware tests [15-17]. In the case of the computer simulations, there are significant errors between simulation and experimental results since they are only based on theoretical models in virtual space which is not the same as the real world. In field experiments and stand-alone hardware implementations, practical tests are limited to specific environments due to spatial scales and cost restrictions. In particular, power tests that simulate fault conditions in a real power grid can be dangerous. Therefore, it is difficult to guarantee the accuracy of simulation results. 


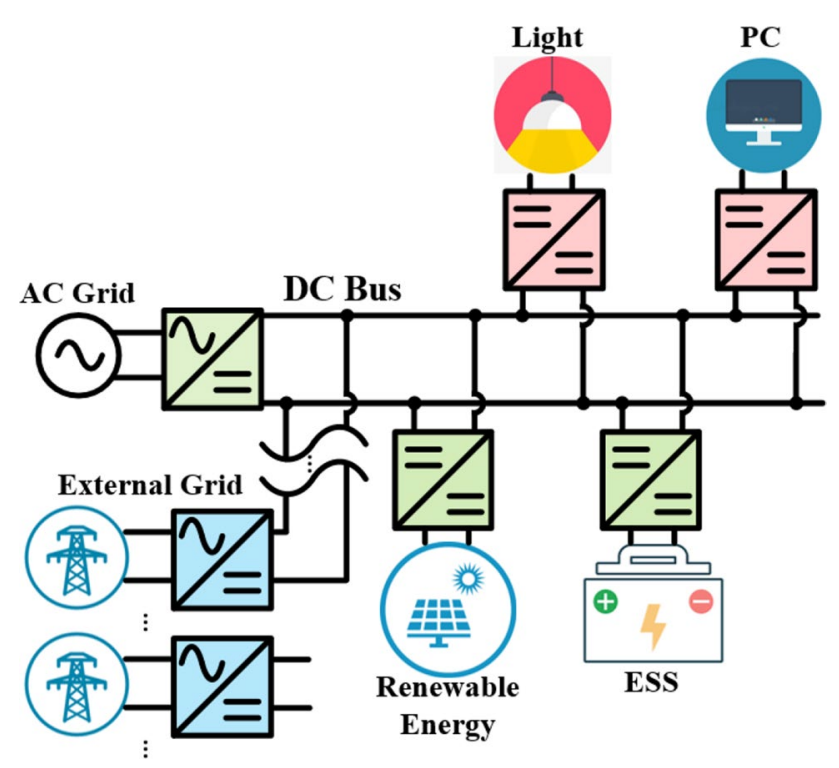

Fig. 1 Conceptual structure of a 20-kW DC nano grid system

To overcome these limitations, the concept of power hardware-in-the-loop (PHIL) simulation has been proposed [18]. Unlike off-line software simulations, which use a virtual converter model, PHIL simulations can provide a variety of test conditions using real converter hardware [19]. In addition, the operation of an entire grid system can be easily simulated by considering fault conditions, which cannot be performed in field experiments or standalone hardware tests.

Several studies related to PHIL simulation have been conducted [18, 20, 21]. A battery and electric vehicle based on PHIL simulation have been proposed to show their feasibility [20]. DC grid research based on a PHIL test-bed has been proposed [18, 21]. As reported in [21], the supply strategy of renewable energy has been analyzed using a PHIL wind turbine model in a DC grid. In the case of [18], a DC grid was constructed using PHIL simulation technology and its behavior in grid-connected and island modes was analyzed. However, an overall test-bed for testing control algorithms and grid fault conditions based on a PHIL simulation, which can validate the reliability of a DC power grid, has not been proposed yet.

In this paper, an overall DC grid test-bed system based on the PHIL simulation technique is proposed to verify the reliability of a 20-kW DC nano grid with grid-connected converters. Each grid-connected converter is designed to verify the test-bed performance for testing the autonomous operation of the DC nano grid. Finally, using a $3-\mathrm{kW}$ prototype test-bed, the grid-connected mode, islanding mode and abnormal operating conditions such as grid failures are designed and implemented to verify the reliability of the proposed DC nano grid.

\section{DC nano grid test-bed}

The proposed PHIL test-bed system for a DC nano grid consists of an ESS system, a DC load, an AC/DC and DC/DC converter connected to an external grid and a PHIL simulation system including a PHIL AC/DC converter as shown in Fig. 2. The PHIL simulation system is mainly used to control the DC bus voltage, and the AC/DC and DC/DC converter connected to external grids is used to simulate the external grid and the renewable energy simulator according to the mode operations of the DC nano grid.

\subsection{PHIL system: PHIL AC/DC converter}

The AC/DC converter plays a role in the interaction between a DC nano grid and an AC grid. However, it is dangerous to conduct experiments on fault conditions such as blackouts or short-circuits. To verify stability and reliability under fault conditions, a PHIL simulation is used to obtain the AC/DC converter model for simulating an actual 20-kW DC nano grid, called a PHIL AC/DC converter in this paper. Figure 3 shows the PHIL simulation model of an AC/DC converter. An AC voltage of $220 \mathrm{~V}$ is supplied to a voltage source converter (VSC) by stepping down $25 \mathrm{kV}$ from the utility grid. In addition, an input LC filter is added to eliminate input

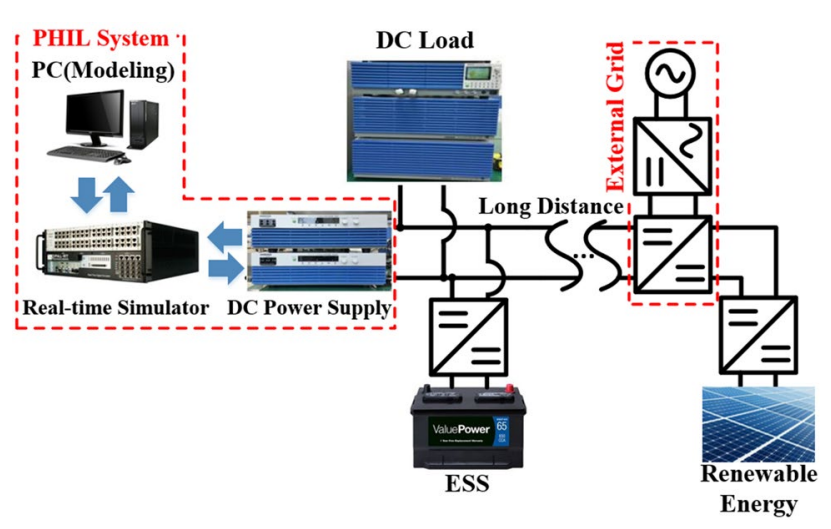

Fig. 2 Conceptual structure of a PHIL simulation system

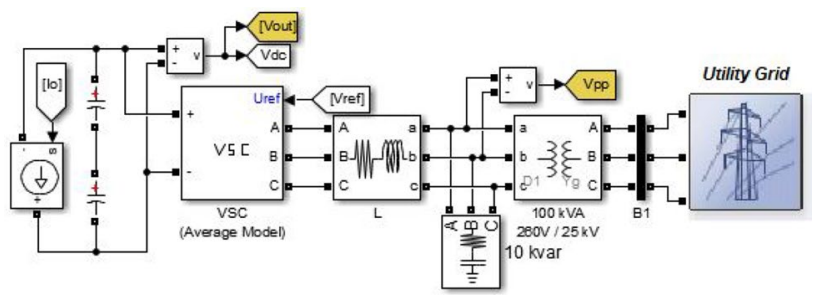

Fig. 3 PHIL simulation model of an AC/DC converter 


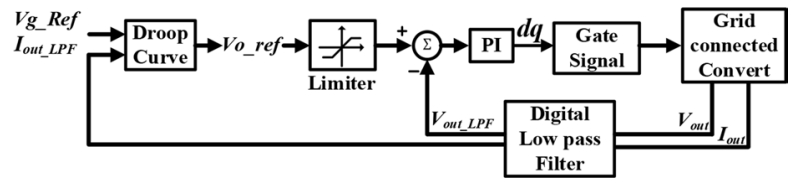

Fig. 4 Control algorithm of the AC/DC converter used in a PHIL simulation

Table 1 Specification of a PHIL AC/DC converter

\begin{tabular}{ll}
\hline Parameter & Value \\
\hline Grid voltage & $220 \mathrm{Vrms}$ \\
Grid frequency & $60 \mathrm{~Hz}$ \\
DC-link voltage (DC bus) & $380 \mathrm{~V}$ \\
Output power & $20-\mathrm{kW}$ \\
\hline
\end{tabular}

voltage harmonics. As shown in Fig. 4, the output voltage and current with the power factor control of the VSC are regulated by an external voltage controller and an internal current controller, respectively.

Table 1 shows the specification of the AC/DC converter used in the PHIL simulator. As shown in Table 1, the AC/ DC converter gets electric power from an AC $220 \mathrm{~V}$ and provides DC $380 \mathrm{~V}$ to the DC bus. It is modeled with a rated power of 20-kW: $52.6 \mathrm{~A}$ at DC $380 \mathrm{~V}$. However, the rated current of 52.6 A in the PHIL AC/DC converter is matched to $7.8 \mathrm{~A}$ in an actual manner by a power amplifier constructed by a programmable power supply. In a laboratory test, the DC nano grid is designed to be $3-\mathrm{kW}$ due to lab facility limitations.

\subsection{Energy storage system: current-fed dual active bridge converter}

An ESS is required to supply stable power to the DC bus in the event of irregular power generation from renewable energy and grid failure. In addition, the ESS absorbs electric energy when surplus energy occurs, which can manage the electric energy efficiently. Therefore, a bi-directional DC/ $\mathrm{DC}$ converter is required to charge and to discharge electric power [22]. In this paper, a current-fed dual active bridge (CF-DAB) converter, as shown in Fig. 5, is used for regulating bi-directional power flows since this topology has several advantages. It can obtain a unit voltage gain based on the pulse width modulation of the battery side switches, which allows the switches to achieve zero voltage switching (ZVS). In addition, the $\mathrm{CF}-\mathrm{DAB}$ converter can reduce current ripples on the battery side due to its inductive filters. The power flow transition is smooth and simple by using single-phase shift modulation (SPSM). The design specification of the proposed CF-DAB converter is shown in Table 2.

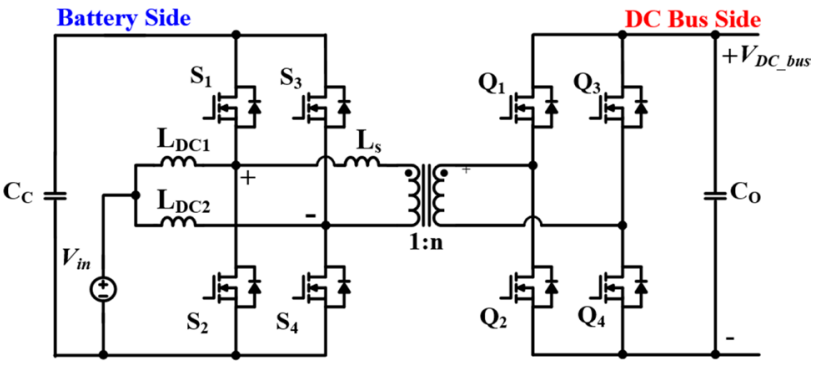

Fig. 5 Circuit diagram of a current-fed DAB converter

Table 2 Specification of a CF-DAB converter

\begin{tabular}{ll}
\hline Parameter & Value \\
\hline Input voltage (ESS) & $50-60 \mathrm{~V}$ \\
Output voltage (DC bus) & $380 \mathrm{~V}$ \\
Output power & $1-\mathrm{kWh}$ \\
\hline
\end{tabular}

In the grid-connected mode, the ESS is charged and discharged through the CF-DAB converter according to the load conditions. In the islanding mode, the power flow from the main grid is stopped, and the DC bus voltage decreases. The DC bus voltage can be controlled by the ESS through the CF-DAB converter. In this paper, the islanding mode means that the main grid controlled by the PHIL simulation system is under a blackout. Then the DC bus voltage decreases and the ESS becomes the main voltage source to regulate the DC bus. If the electric energy stored in the ESS is infinite, the DC nano grid can operate well in the islanding mode. However, the energy capacity of an ESS is finite. When the ESS is fully discharged, the DC bus voltage cannot be regulated by the ESS.

\subsection{External grid and renewable energy simulator: $A C / D C$ and $D C / D C$ converter}

\subsubsection{External grid mode}

To prevent blackouts of the DC nano grid, the external grid connected to the DC nano grid is additionally configured as shown in Fig. 1. In this paper, the feasibility of the DC nano grid linked to the external grid is verified. In addition, it is shown that the proposed test-bed is more reliable when compared with the conventional DC nano grid by using the proposed control algorithm considering the external grid. To implement the external grid in practice, a bi-directional $\mathrm{AC} /$ DC converter is required to absorb and to supply the power from the DC nano grid. In addition, as shown in Fig. 6, the DC/DC converter is required to obtain a high-power density with galvanic isolation by using a high-frequency 


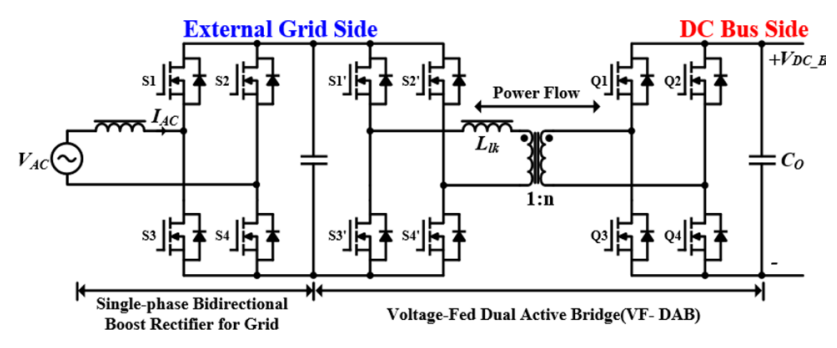

Fig. 6 Circuit diagram of AC/DC and DC/DC converters

Table 3 Specification of an AC/DC and DC/DC converter

\begin{tabular}{ll}
\hline Parameter & Value \\
\hline Input voltage (AC grid) & $220 \mathrm{Vrms}$ \\
Output voltage (DC bus) & $380 \mathrm{~V}$ \\
Output power & $3-\mathrm{kW}$ \\
\hline
\end{tabular}

transformer [22]. The design specifications of the AC/DC and DC/DC converter are shown in Table 3.

The AC/DC converter adopts a single-phase bi-directional boost converter topology using sinusoidal pulse width modulation. It controls the reactive power to be zero with a unity power factor. A voltage-fed dual active bridge (VF$\mathrm{DAB}$ ) converter, which uses the SPSM, is selected as the bi-directional DC/DC converter. This is due to the fact that the power flows can easily be controlled by the phase difference between the primary and secondary side with a fixed duty of $50 \%$. In addition, all of the switches of the VF-DAB converter operate in the ZVS area since the input and output voltage of the VF-DAB converter are the same as $380 \mathrm{~V}$, i.e., the unit voltage gain in the grid-connected mode is achieved [23].

\subsubsection{Renewable energy simulator mode}

The AC/DC and DC/DC converter represents a renewable energy simulator as shown in the shaded area of Fig. 7. To simulate renewable energy connected to external grids, the bidirectional AC/DC and DC/DC converter generates triangular current, which reproduces irregular power generation during the grid-connected mode operation.

When the amount of the power generation of the renewable energy in the external grid is larger than the desired amount of the external load power, the surplus energy from the external grid can be supplied to the main grid. In the case of the islanding mode, when the ESS is fully discharged as explained, the DC bus voltage will be collapsed. In order to prevent a blackout, the AC/DC and DC/DC converter operates as an external grid so that the $\mathrm{DC}$ bus voltage can be regulated. Therefore, in this paper, the AC/DC and DC/DC converter can operate as a renewable energy simulator and

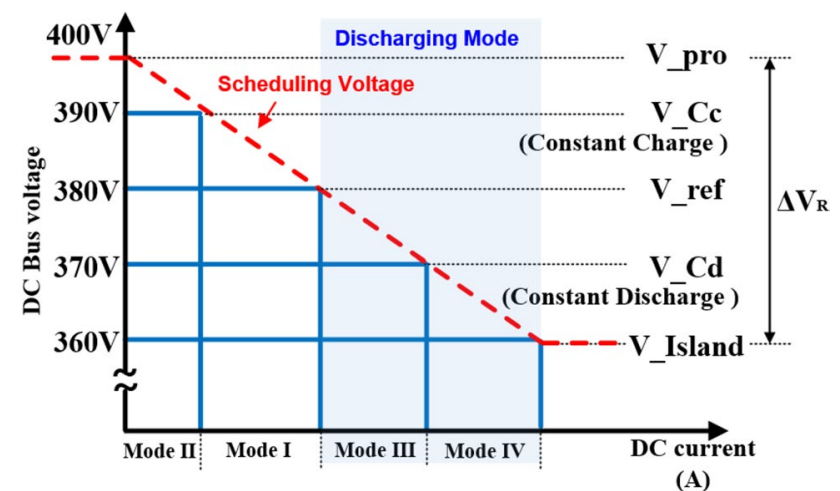

Fig. 7 Operating modes of a DC nano grid according to its DC bus voltage

an external grid according to the grid-connected mode and the islanding mode, respectively.

\subsection{Power management strategy of the DC nano grid test-bed}

As shown in Fig. 1, since the DC nano grid has a variety of loads and different power sources connected to the DC bus, an effective power management strategy is required. To achieve stability and reliability of the DC grid, the DC bus signaling (DBS) control shown in Fig. 4 is employed as a droop control block [24-27]. The DBS control operates based on a voltage droop algorithm using the DC bus voltage level. The grid power can be easily controlled by the DBS control without any communication devices. Using the DBS control, the converters connected to the grid can operate according to the DC bus voltage level and can independently work mutually with other converters on the same DC bus. Finally, autonomous operation of the DC nano grid can be achieved [28].

Figure 7 shows the DBS algorithm employed in this paper. DC bus voltage changes from 360 to $390 \mathrm{~V}$ according to the load current. The DBS algorithm is applied to the PHIL system as shown in Fig. 4. The controller of the AC/ DC converter receives the information of $V_{\text {O_ref }}$ determined by the load as follows:

$$
V_{\mathrm{O} \_ \text {ref }}=V_{\mathrm{DC} \_ \text {nom }}-K_{\mathrm{d}} I_{\mathrm{O}} \text {, }
$$

where $V_{\text {DC_nom }}$ is the nominal DC bus voltage, which is $380 \mathrm{~V}$ in this paper, $V_{\mathrm{O}_{\text {ref }}}$ is the reference value, $K_{\mathrm{d}}$ and $I_{\mathrm{O}}$ are the droop coefficient and load current flowing to the DC bus, respectively. Depending on the DC bus voltage, the operating modes of the DC nano grid are divided into four cases. Mode I (power supply by the main grid and renewable energy), mode II (charge operation by the ESS due to surplus energy), mode III (power supply by the main grid, 
the renewable energy and the ESS), and mode IV (when the main grid is under a blackout, i.e., the islanding mode). Each mode of operation is described in detail in the following section.

\section{Grid code operation}

In this paper, a DBS control algorithm is employed for the reliable operation of a DC nano grid under various load conditions such as blackouts. The PHIL test-bed, which can simulate a DC nano grid, controls the output voltage of the grid-connected converter. The operational modes are listed in the previous paragraph. The operation of each grid component is summarized in Table 4.

The constant voltage (CV) mode and the constant current (CC) mode in Table 4 indicate the control status of the converter connected to the DC bus. When multiple converters on the same DC bus are in the CV mode, their controls can conflict with each other. For example, when one converter is in the CV mode, the other should operate in the CC mode to avoid conflicting with the power control in the same DC grid. When the VSC of the PHIL system operates as a voltage source to control the DC bus voltage, as shown in Fig. 7, the other converters should operate in the $\mathrm{CC}$ mode, which supplies energy to the DC bus or absorb energy from the DC bus.

1. Mode I: the DC bus voltage is located between 370 and $380 \mathrm{~V}$. In Mode I, the main grid operates as the main energy source and renewable energy supports the power supplied from the main grid. The PHIL system, which simulates the main grid, operates as a voltage source and controls the DC bus voltage. In addition, as explained in Sect. 2.3, since the AC/DC and DC/DC converter operates as a renewable energy simulator in this mode, the external grid supplies energy to the DC bus as a current source. In mode I, the amount of load is greater than the generated power from renewable energy. Therefore, load current flows to the DC bus as much as the difference between the amount of the load and the power generated from renewable energy. The DC bus voltage changes according to the load conditions shown in (1), which determines the output voltage of the VSC. As a result, the output voltage of the VSC in Fig. 3 is controlled to the reference voltage. If the amount of the load increases continuously, the DC bus voltage gradually decreases from 380 to $370 \mathrm{~V}$. Then the operating mode switches to mode III.

2. Mode II: the DC bus voltage is located between 380 and $390 \mathrm{~V}$. In mode II, unlike mode I, the generated renewable energy in the external grid is greater than the amount of load connected to the DC bus. As a result, the ESS is charged due to surplus energy. However, when the ESS is fully charged, the operation of the DC/DC converter connected to the ESS shown in Fig. 5 stops. If renewable energy generates surplus energy continuously without considering the ESS charging status, the DC bus voltage can increase due to excessive energy. At that time, the AC/DC and DC/DC converter shown in Fig. 6 should stop power generation from renewable energy to prevent dangerously increasing the DC bus voltage level by cutting off the supply of surplus energy to the main grid.

3. Mode III: the DC bus voltage is located between 360 and $370 \mathrm{~V}$. In mode III, power is supplied from the ESS and renewable energy to support load increments. As explained in Sect. 2, the ESS is discharged by the CFDAB converter connected to the DC bus to supply power to the load under the CC mode. When the ESS is discharged, the state of charge (SOC) of the ESS gradually decreases. When the battery voltage reaches the minimum SOC, the DC/DC converter connected to the ESS stops discharging to protect the ESS. As a result, the DC bus voltage can be decreased up to $360 \mathrm{~V}$. Then the operating mode switches to mode IV.

4. Mode IV: the DC bus voltage hits $360 \mathrm{~V}$. In mode IV, abnormal cases such as blackouts are simulated to verify
Table 4 Operating components and their status depending on the operating modes

\begin{tabular}{|c|c|c|c|}
\hline & $\begin{array}{l}\text { PHIL system in Fig. } 2 \\
\text { (Main grid, AC/DC con- } \\
\text { verter in Fig. 3) }\end{array}$ & $\begin{array}{l}\text { ESS in Fig. } 2 \\
\text { (DC/DC converter in Fig. 5) }\end{array}$ & $\begin{array}{l}\text { Another grid in Fig. } 2 \\
\text { (AC/DC and DC/DC con- } \\
\text { verters in Fig. } 6 \text { ) }\end{array}$ \\
\hline \multirow{2}{*}{$\begin{array}{l}\text { Mode I } \\
(370-380 \mathrm{~V})\end{array}$} & $\mathrm{CV}$ mode & OFF & Renewable energy simulator \\
\hline & $\mathrm{CV}$ mode & OFF & Renewable energy simulator \\
\hline \multirow{2}{*}{$\begin{array}{l}\text { Mode II } \\
(380-390 \mathrm{~V})\end{array}$} & $\mathrm{CV}$ mode & Stand-by (Max SOC) & Renewable energy simulator \\
\hline & CV mode & $\begin{array}{l}\text { CC mode } \\
\text { (charging/discharging) }\end{array}$ & Renewable energy simulator \\
\hline \multirow{2}{*}{$\begin{array}{l}\text { Mode III } \\
(360-370 \mathrm{~V})\end{array}$} & $\mathrm{CV}$ mode & CC Mode (discharging) & Renewable energy simulator \\
\hline & $\mathrm{CV}$ mode & Stand-by (Min Soc) & Renewable energy simulator \\
\hline \multirow{2}{*}{$\begin{array}{l}\text { Mode IV } \\
(<360 \mathrm{~V})\end{array}$} & Main grid outage (OFF) & Islanding mode (CV mode) & Renewable energy simulator \\
\hline & Main grid outage (OFF) & Fully discharged (OFF) & Another grid (CV mode) \\
\hline
\end{tabular}


the autonomous operation of the proposed PHIL testbed. When the main grid is disconnected due to blackouts, the operation of the DC nano grid is changed from the grid-connected mode to the islanding mode. In the islanding mode, the DC nano grid is controlled by the ESS or the external grid depending on the ESS conditions in mode III. If a blackout occurs on the main grid during the discharging operation of the ESS in mode III, the operation mode is switched to mode IV. As soon as mode III is switched to mode IV, the CF-DAB converter connected to the ESS changes its operating mode from the $\mathrm{CC}$ mode to the $\mathrm{CV}$ mode to regulate the $\mathrm{DC}$ bus voltage. As a result, the DC bus is controlled to $380 \mathrm{~V}$ by the ESS. However, if the ESS is fully discharged, the DC bus voltage can be collapsed below $360 \mathrm{~V}$, resulting in a blackout of the entire grid. Therefore, to prevent a blackout of the entire grid, as soon as the DC bus voltage reaches $360 \mathrm{~V}$, the external grid is connected to the DC bus and provides power to the load. The AC/DC and DC/DC converter switches its operation from the CC mode to the $\mathrm{CV}$ mode. As a result, the DC bus voltage is controlled to $380 \mathrm{~V}$ by the external grid.

\section{PHIL simulation and experimental results}

To verify the reliability of the proposed $20-\mathrm{kW}$ DC nano grid test-bed, a small grid is configured with an OP5600 real-time simulator manufactured by Opal-RT, a programmable uni-directional DC power supply, a DC load, an ESS, and an AC/DC and DC/DC converter, which are connected to the DC bus as shown in Fig. 8. The long-distance line can be modeled using the resistance [28]. In this paper, the long-distance line is reproduced with a $1-\mathrm{Ohm}$ resistor. To

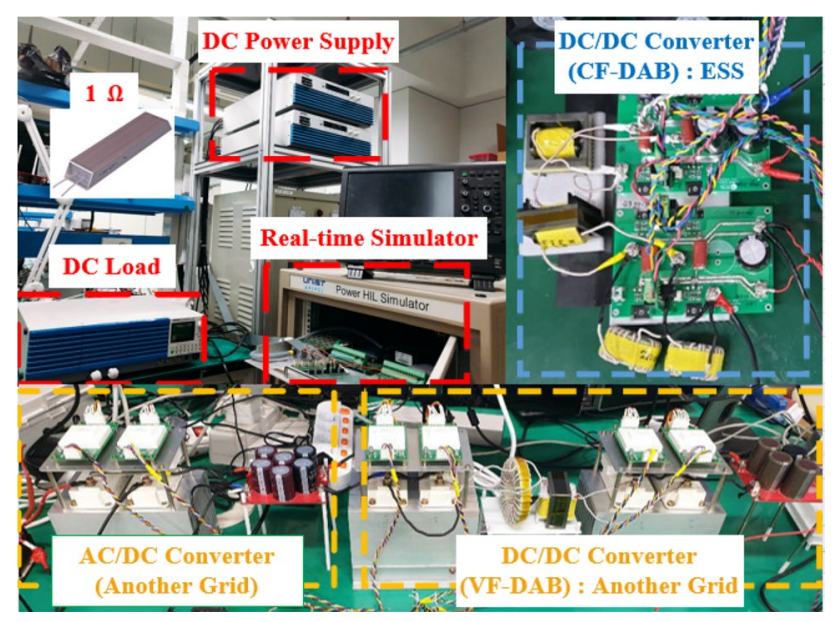

Fig. 8 Virtual test-bed of a DC nano grid using a PHIL simulation implement a simplified test-bed, the transmission line capacitance and inductance are neglected.

In the case of the PHIL simulation, the $20-\mathrm{kW}$ grid is modeled to simulate a DC nano grid. Through the power amplifier conducted by the programmable power supply, the emulated $20-\mathrm{kW}$ grid is matched with a real $3-\mathrm{kW}$ grid to implement the entire grid based on the prototype gridconnected converters. In this research environment, since the uni-directional programmable DC power supply has a limited power capacity, the only the discharge operation of the ESS is considered.

\subsection{Case A: ESS discharging operation}

Figure 9 shows experimental waveforms of a mode transition from Mode I to Mode III, assuming the situation where the ESS supports power to the main grid. Figure 9a, b shows waveforms of the DC bus and the ESS, respectively. As can be seen in Fig. 9, the PHIL system supplies power according to the amount of load. When the grid operating mode enters into mode III, the CF-DAB converter connected to the DC bus operates under the CC mode and the ESS discharges with a constant current of $1.5 \mathrm{~A}$. Therefore, the PHIL system provides as much as the difference between the amount of the total load and the energy supplied by the ESS.

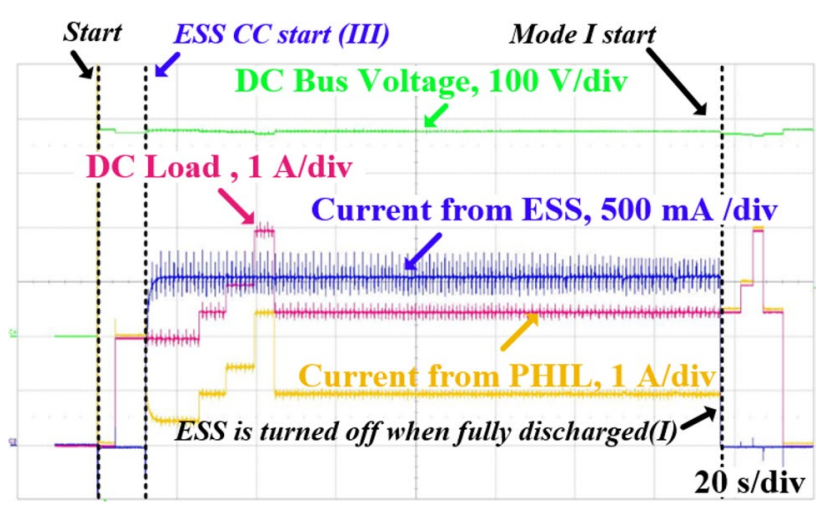

(a)

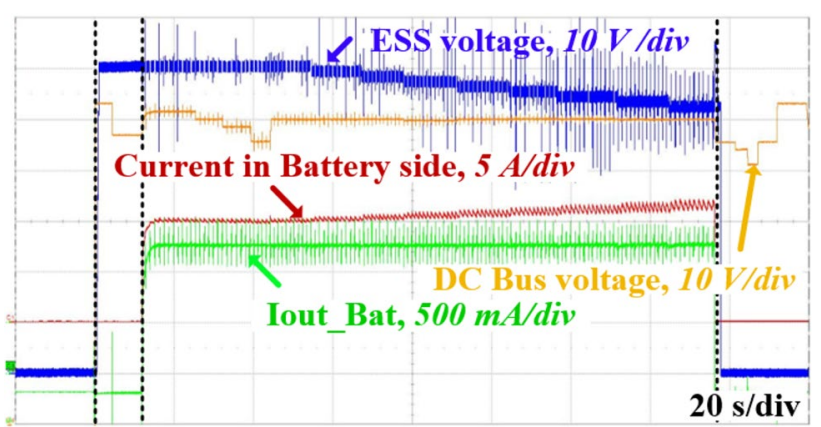

(b)

Fig. 9 Experimental waveforms of a mode transition from Mode I to Mode III: a DC bus; b ESS 
In Fig. 9a, it can be seen that the main grid and the ESS operate by a scheduled DBS. In addition, in Fig. 9b, although the ESS voltage level decreases over time, the ESS can supply a constant current since the CF-DAB controls the duty ratio of the primary switch to provide a constant power regardless of the input voltage. However, continuous ESS operation causes the ESS voltage to reach its minimum SOC voltage level. In Fig. 9a, when the ESS stops, the total energy is supplied by the PHIL system, resulting in a DC voltage drop. Based on experimental results of the proposed test-bed shown in Fig. 9, the proper operation of the scheduled DBS including the ESS discharging operation can be demonstrated.

\subsection{Case B: islanding mode controlled by the ESS}

Figure 10 shows experimental waveforms of a mode transition from mode I to mode IV, assuming a sudden main grid blackout. Figure 10a, b shows waveforms of the DC bus and the ESS, respectively. In Fig. 10, the DC bus voltage is controlled by the scheduled DBS according to load variations. In mode I, the PHIL system deliver power to the DC bus; and in Mode III, the ESS discharges with a constant current as $1.5 \mathrm{~A}$.

Even in blackout conditions where the current from the PHIL system is stopped, as shown in Fig. 10, the DC bus

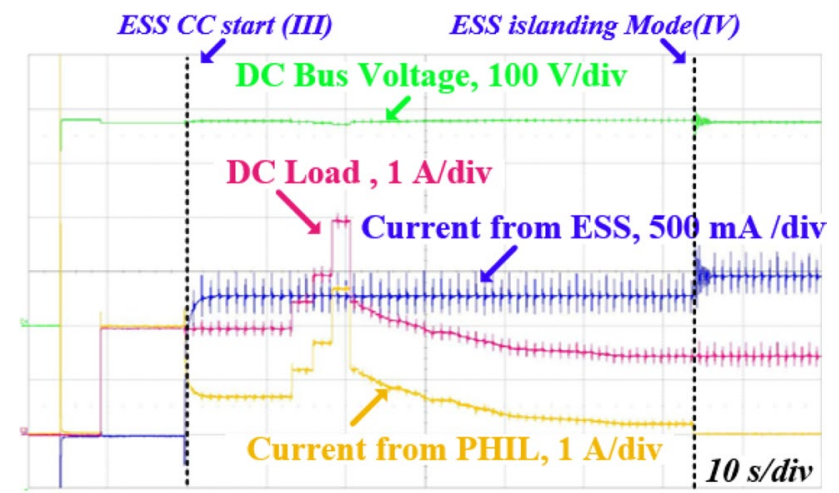

(a)

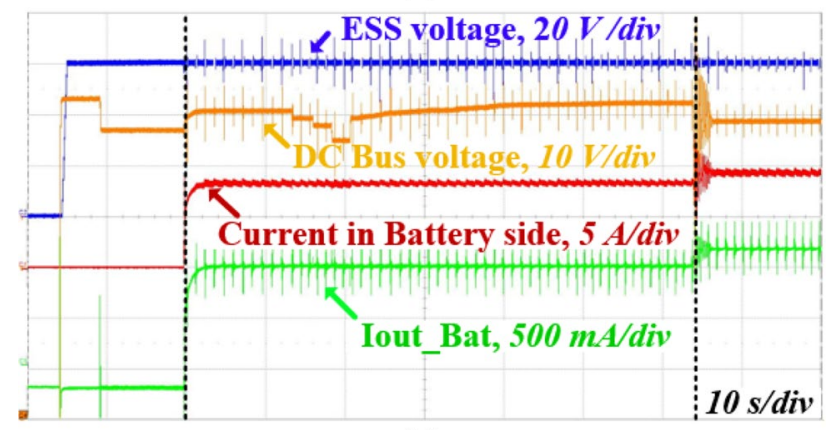

(b)

Fig. 10 Experimental waveforms of a mode transition from mode I to mode IV (ESS islanding): a DC bus; $\mathbf{b}$ ESS voltage can maintain a constant value of $380 \mathrm{~V}$. This means that the ESS controls the DC bus voltage using the CF-DAB converter under the $\mathrm{CV}$ mode. This means that the proposed DC grid test-bed can continuously provide power to the DC grid even in the event of accident situations, such as power outages, through seamless mode transitions.

\subsection{Case C: supply of renewable energy}

Compared to case A and case B, surplus energy by renewable energy of the external grid is additionally considered in case C. Figure 11 shows a mode change from mode I to mode IV (ESS islanding) with the generation of renewable energy. Figure 11a-c shows waveforms of the ESS, the AC/ DC and DC/DC, and the DC bus, respectively. As shown in Fig. 11c, in mode I, the PHIL system supplies a $2 \mathrm{~A}$ current to the load, and the ESS discharges with constant

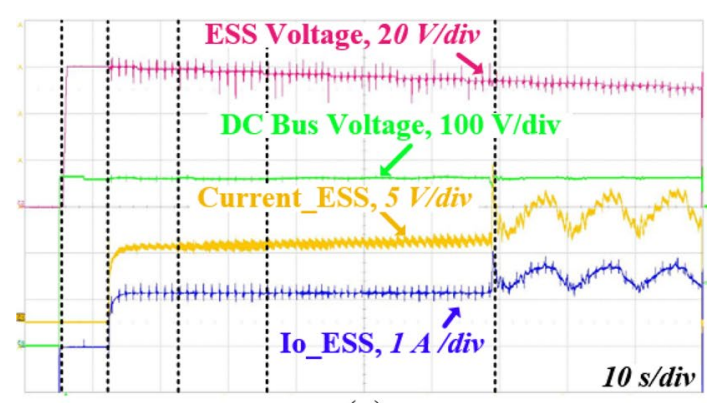

(a)

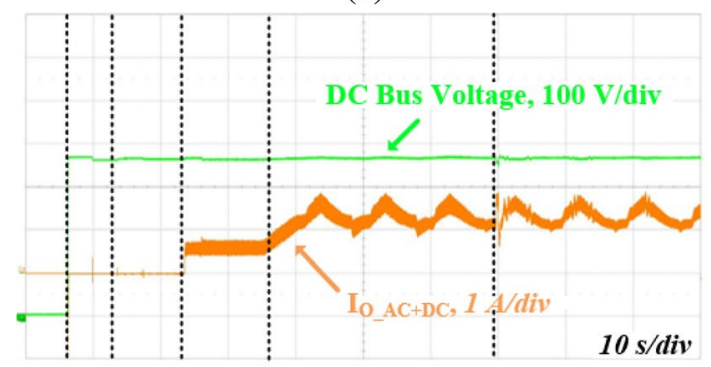

(b)

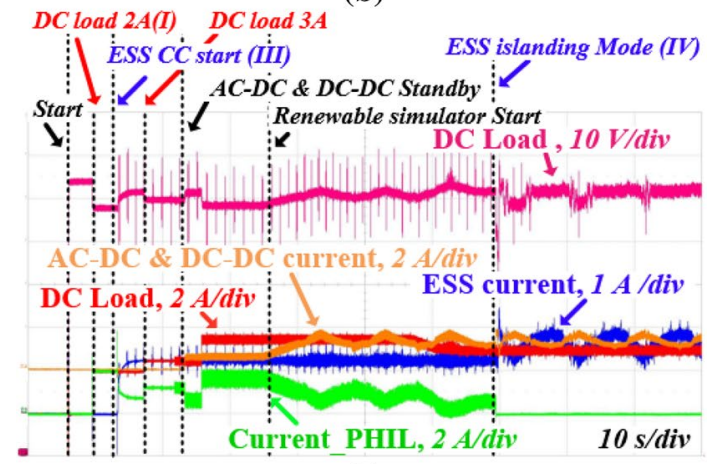

(c)

Fig. 11 Experimental waveforms (including a renewable energy supply) of a mode transition from mode I to mode IV (ESS islanding): a ESS; $\mathbf{b} \mathrm{AC} / \mathrm{DC}$ and DC/DC; $\mathbf{c}$ DC bus 
current of 1.2 A in mode III. After the ESS operates under the CC mode in mode III, as shown in Fig. 11c, the remaining energy is delivered from renewable sources from the external grid to the $\mathrm{DC}$ bus through the AC/DC and DC/ DC converter. Here, as explained in Sect. 2.3.2, to simulate irregular power, a triangle waveform is generated by the $\mathrm{AC} /$ $\mathrm{DC}$ and DC/DC converter, which changes from 1 to $2 \mathrm{~A}$ where the energy is delivered from the external grid to the main grid. The PHIL system provides as much power as the difference between the total amount of the load and the sum of the current supplied by the ESS and the external grid. In addition, the ESS delivers as much power as the difference between the total amount of the load and the current supplied by renewable energy.

This means that renewable energy can be continuously delivered regardless of the grid-connected mode and the islanding mode, sharing the amount of load on the DC bus.

\subsection{Case D: islanding mode with a connecting external grid}

A fully discharged ESS is considered in case D. Figure 12 shows experimental waveforms of the mode transition from mode I to mode IV (external grid islanding). Figure 12a-c shows waveforms of the ESS, the AC/DC and DC/DC, and the DC bus, respectively. As can be seen in Fig. 12, when the DC bus voltage is regulated by the PHIL system, the surplus energy (1-2 A) of the external grid and the ESS energy (constant current of $1.2 \mathrm{~A}$ ) are supplied by scheduled DBS depending on the amount of the load. In addition, the power delivered from the PHIL system changes depending on the energy from the ESS and the external grid. When the main grid becomes blackout, the ESS controls the DC bus, and the output power of the ESS is changed depending on the surplus energy of the external grid. When the ESS reaches its minimum SOC, the DC bus voltage decreases. Here, as explained in Sect. 2.3.1, the operating mode of the $\mathrm{AC} / \mathrm{DC}$ and $\mathrm{DC} / \mathrm{DC}$ converter changes from the $\mathrm{CC}$ mode (renewable energy simulator) to the $\mathrm{CV}$ mode (external grid) to regulate the DC bus voltage. The DC bus voltage level is kept within its proper operation range by using the external grid even when the ESS is fully discharged. This means that the autonomous operations of the proposed test-bed are verified.

\section{Conclusion}

In this paper, a test-bed, consisting of a PHIL system, a 1-kW CF-DAB converter, a 3-kW single-phase boost converter, and a $3-\mathrm{kW}$ VF-DAB converter is proposed. Using the proposed system, the autonomous operation of a DC nano grid can be simulated. Experiments are carried out to

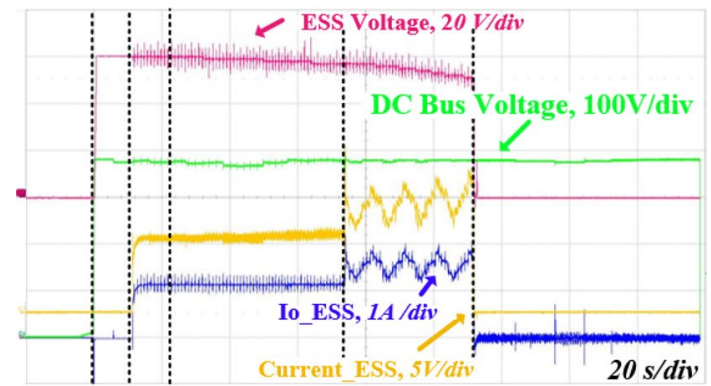

(a)

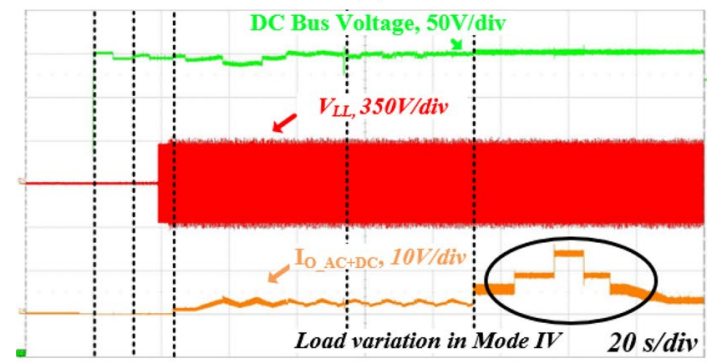

(b)

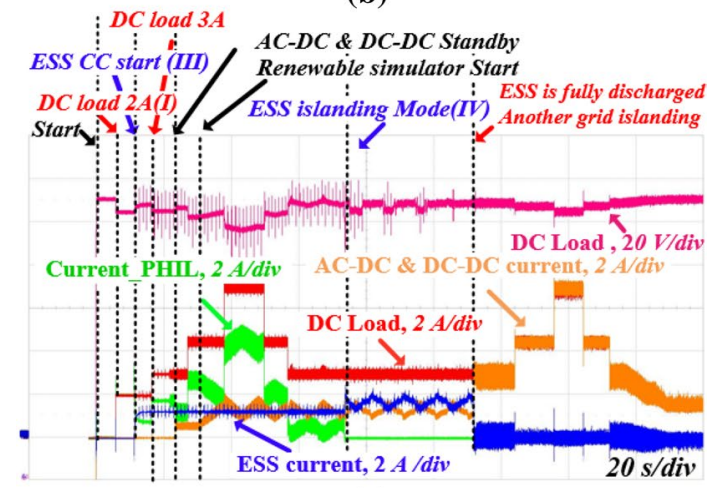

(c)

Fig. 12 Experimental waveforms (including a renewable energy supply) of a mode transition from mode I to mode IV (external grid islanding): a ESS; $\mathbf{b} \mathrm{AC} / \mathrm{DC}$ and $\mathrm{DC} / \mathrm{DC} ; \mathbf{c} \mathrm{DC}$ bus

demonstrate the reliability of the proposed test-bed based on several operating conditions with the scheduled DBS algorithm. Seamless mode transitions are implemented according to the DBS algorithm. As a result, although power from the main grid is stopped, the DC bus voltage is regulated within suitable operation ranges between 360 to $380 \mathrm{~V}$ without any voltage collapse. This means that the reliability of the proposed test-bed is suitable for testing the DC nano grid. In addition, the feasibility of the PHIL system and the external grid are verified under several operating cases such as the supply of renewable energy and a fully discharged ESS. In conclusion, the proposed test-bed, autonomously operated with the power HIL simulator, is verified.

Acknowledgements This work was supported by the energy efficiency and resources of the Korea Institute of Energy Technology Evaluation 
and Planning (KETEP) grant funded by the Korea government Ministry of Knowledge Economy. (No. 20192010106750).

\section{References}

1. Ballal, M.S., Bhadane, K.V., Moharil, R.M., Suryawanshi, H.M.: A control and protection model for the distributed generation and energy storage systems in microgrids. J. Power Electron. 16(2), 748-759 (2016)

2. Liu, G., Khodamoradi, A., Mattavelli, P., Caldognetto, T., Magnone, P.: Plug and play DC-DC converters for smart DC nanogrids with advanced control ancillary services. In: 2018 IEEE 23rd international workshop on computer aided modeling and design of communication links and networks (CAMAD), Barcelona, pp. 1-6.P (2018)

3. Lucía, Ó., Cvetkovic, I., Sarnago, H., Boroyevich, D., Mattavelli, P., Lee, F.C.: Design of home appliances for a DC-based nanogrid system: an induction range study case. IEEE J. Emerg. Sel. Top. Power Electron. 1(4), 315-326 (2013)

4. Teleke, S., Oehlerking, L., Hong, M.: Nanogrids with energy storage for future electricity grids. In: 2014 IEEE PES T\&D conference and exposition, chicago, IL, pp. 1-5 (2014)

5. Eghtedarpour, N., Farjah, E.: Distributed charge/discharge control of energy storages in a renewable-energy-based DC micro-grid. IET Renew. Power Gener. 8(1), 45-57 (2014)

6. Xie, B., Wang, J., Jin, Y., Ji, Y., Ma, C.: Power distribution control scheme for a three-phase interleaved DC/DC converter in the charging and discharging processes of a battery energy storage system. J. Power Electron. 18(4), 1211-1222 (2018)

7. Kim, K., Shin, D., Lee, J., Lee, J.-P., Yoo, D.-W., Kim, H.-J.: A seamless transfer algorithm based on frequency detection with feedforward control method in distributed generation system. J. Power Electron. 15(4), 1066-1073 (2015)

8. Li, Z., Zang, C., Zeng, P., Yu, H., Li, H., Li, S.: Analysis of multiagent-based adaptive droop-controlled AC microgrids with pscad: modeling and simulation. J. Power Electron. 15(2), 455-468 (2015)

9. Werth, A., Kitamura, N., Tanaka, K.: Conceptual study for open energy systems: distributed energy network using interconnected DC nanogrids. IEEE Trans. Smart Grid 6(4), 1621-1630 (2015)

10. Navarro-Rodríguez, Á., García, P., Georgious, R., García, J.: Adaptive active power sharing techniques for DC and AC voltage control in a hybrid DC/AC microgrid. IEEE Trans. Ind. Appl. 55(2), 1106-1116 (2019)

11. Buso, S., Caldognetto, T., Liu, Q.: Analysis and experimental characterization of a large-bandwidth triple-loop controller for grid-tied inverters. IEEE Trans. Power Electron. 34(2), 1936-1949 (2019)

12. Chandrasena, R.P.S., Shahnia, F., Ghosh, A., Rajakaruna, S.: Operation and control of a hybrid AC-DC nanogrid for future community houses. In: 2014 Australasian universities power engineering conference (AUPEC), Perth, WA, pp. 1-6 (2014)

13. Jie, L.R., Naayagi, R.T.: Nanogrid for energy aware buildings. In: 2019 IEEE PES GTD grand international conference and exposition Asia (GTD Asia), Bangkok, Thailand, pp. 92-96 (2019)

14. Wang, X., Guerrero, J.M., Blaabjerg, F., Chen, Z.: A review of power electronics based microgrids. J. Power Electron. 12(1), 181-192 (2012)

15. Palmintier, B., Lundstrom, B., Chakraborty, S., Williams, T., Schneider, K., Chassin, D.: A power hardware-in-the-loop platform with remote distribution circuit cosimulation. IEEE Trans. Ind. Electron. 62(4), 2236-2245 (2015)
16. Strasser, T., Stifter, M., Andrén, F., Palensky, P.: Co-simulation training platform for smart grids. IEEE Trans. Power Syst. 29(4), 1989-1997 (2014)

17. Salas, V., Debora, P., Olías, E.: Field analysis of commercial $\mathrm{PV}$ inverters in the $5 \mathrm{~kW}$ power range with respect to MPPT effectively. In: Proceedings of 13th European Conference on power electronics and applications, pp. 1-7 (2009)

18. Wang, J., Song, Y., Li, W., Guo, J., Monti, A.: Development of a universal platform for hardware in-the-loop testing of microgrids. IEEE Trans. Ind. Inf. 10(4), 2154-2165 (2014)

19. Bouscayrol, A.: Different types of hardware-in-the-loop simulation for electric drives. In: 2008 IEEE international symposium on industrial electronics, Cambridge, pp. 2146-2151 (2008)

20. Edrington, C.S., Vodyakho, O., Hacker, B.A.: Development of a unified research platform for plug-in hybrid electrical vehicle integration analysis utilizing the power hardware-in-the-loop concept. J. Power Electron. 11(4), 471-478 (2011)

21. Huerta, F., Tello, R.L., Prodanovic, M.: Real-time powerhardware-in-the-loop implementation of variable-speed wind turbines. IEEE Trans. Ind. Electron. 64(3), 1893-1904 (2017)

22. Sousa, T.J.C., Monteiro, V., Martins, J.S., Sepúlveda, M.J., Lima, A., Afonso, J.L.: Comparative analysis of power electronics topologies to interface dc homes with the electrical ac power grid. In: 2019 International conference on smart energy systems and technologies (SEST), Porto, Portugal, pp. 1-6 (2019)

23. Rodríguez, A., Vázquez, A., Lamar, D.G., Hernando, M.M., Sebastián, J.: Different purpose design strategies and techniques to improve the performance of a dual active bridge with phaseshift control. IEEE Trans. Power Electron. 30(2), 790-804 (2015)

24. Kim, Y.W., Kwon, M.H., Park, S.Y., Kim, M.K., Yang, D.K., Choi, S.W., Oh, S.J.: Development of $80 \mathrm{~kW}$ bi-directional hybrid-SIC boost-buck converter using droop control in DC nanogrid. Trans. Korean Inst. Power Electron. 22(4), 360-368 (2017)

25. Le, P.M., Pham, X.H.T., Nguyen, H.M., Hoang, D.D.V., Nguyen, T.D., Vo, D.N.: Line impedance estimation based adaptive droop control method for parallel inverters. J. Power Electron. 18(1), 234-250 (2018)

26. Jia, Y., Li, D., Chen, Z.: Unbalanced power sharing for islanded droop-controlled microgrids. J. Power Electron. 19(1), 234-243 (2019)

27. Choi, H., Jung, J.: Enhanced power line communication strategy for DC microgrids using switching frequency modulation of power converters. IEEE Trans. Power Electron. 32(6), 4140-4144 (2017)

28. Schonbergerschonberger, J., Duke, R., Round, S.D.: DC-bus signaling: a distributed control strategy for a hybrid renewable nanogrid. IEEE Trans. Ind. Electron. 53(5), 1453-1460 (2006)

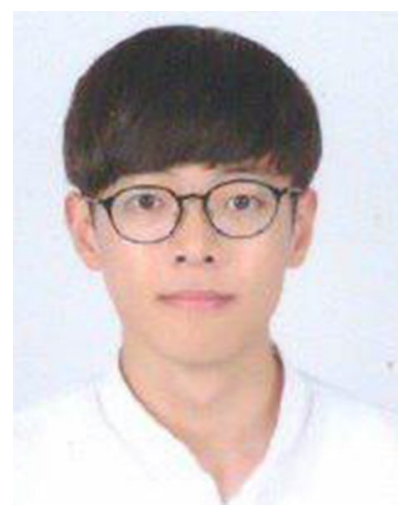

Kyung-Wook Heo was born in Daegu, Korea, in 1994. He received his B.S. degree in Electronic Engineering from the Kumoh National Institute of Technology, Gumi, South Korea, in 2019. He is presently working towards his Ph.D. degree in Electrical Engineering from the Ulsan National Institute of Science and Technology (UNIST), Ulsan, South Korea. His current research interests include bidirectional DC/DC converters for energy storage system(ESS), grid-interactive $\mathrm{AC} / \mathrm{DC}$ and $\mathrm{DC} /$ 
AC power conversion, and real-time and power hardware-in-the-loop (HIL) simulations of power grids.

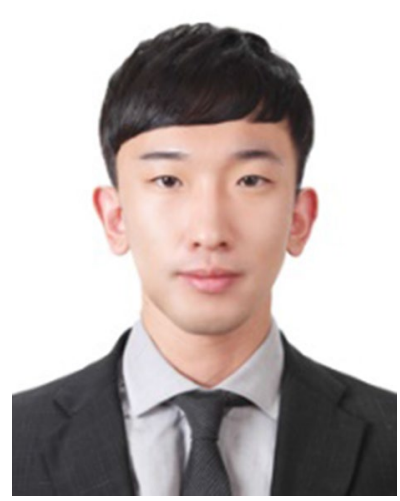

Hyun-Jun Choi was born in Busan, Korea, in 1989. He received his B.S. degree in Electrical and Information Engineering from the Seoul National University of Science and Technology, Seoul, South Korea, in 2013. He is presently working towards his Ph.D. degree in Electrical Engineering from Ulsan National Institute of Science and Technology (UNIST), Ulsan, South Korea. His current research interests include power converters for low voltage DC distribution (LVDC) systems, bidirectional DC/DC converters for energy storage system (ESS), and digital control algorithm for bi-directional power flow.

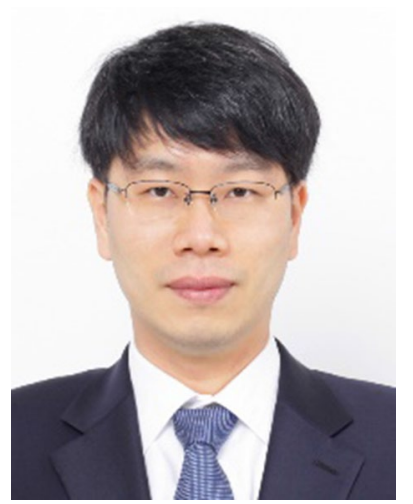

Jee-Hoon Jung was born in Suwon, South Korea, in 1977. $\mathrm{He}$ received his B.S. degree in Electronic and Electrical Engineering and his M.S. and Ph.D. degrees in Electrical and Computer Engineering from the Department of Electronics and Electrical Engineering, Pohang University of Science and Technology (POSTECH), Pohang, South Korea, in 2000, 2002 and 2006, respectively. From 2006 to 2009, he was a Senior Research Engineer in the Digital Printing Division, Samsung Electronics Company Ltd., Suwon, South Korea. From 2009 to 2010, he was a Postdoctoral Research Associate in the Department of Electrical and
Computer Engineering, Texas A\&M University at Qatar (TAMUQ), Doha, Qatar. From 2011 to 2012, he was a Senior Researcher in the Power Conversion and Control Research Center, HVDC Research Division, Korea Electrotechnology Research Institute (KERI), Changwon, South Korea. From 2013 to 2016, he was an Assistant Professor in the School of Electrical and Computer Engineering, Ulsan National Institute of Science and Technology (UNIST), Ulsan, South Korea, where he is presently working an Associate Professor. His current research interests include DC/DC and AC/DC converters, switched-mode power supplies, motor diagnosis systems, digital control and signal processing algorithms, power conversion for renewable energy, and real-time and power hardware-in-the-loop (HIL) simulations of renewable energy and power grids. Recently, he has been researching high-frequency power converters using wide bandgap devices, bidirectional power converters for smart grids, power control algorithms, spread spectrum techniques and power line communications for DC microgrids, and induction heating techniques for home appliances. Dr. Jung is a Senior Member of the IEEE Industrial Electronics Society, the IEEE Power Electronics Society, the IEEE Industry Applications Society, and the IEEE Power and Energy Society. He had served as a Member of the Editorial Committee of the Korea Institute of Power Electronics (KIPE), and an Associate Editor of the Journal of Power Electronics (JPE). He is presently serving as a Member of Board of Directors of the KIPE. In addition, he is an editorial board member for Energies in the Multidisciplinary Digital Publishing Institute (MDPI). 